\title{
Covid-19: the ethics of clinical research in quarantine
}

\author{
Nicholas G Evans argues that research conducted on people in quarantine can produce important \\ scientific information but poses distinct ethical challenges
}

\author{
Nicholas G Evans assistant professor \\ Department of Philosophy, University of Massachusetts Lowell, 883 Broadway Street, Dugan 200F, Lowell MA 01852, USA
}

\begin{abstract}
The ongoing covid-19 outbreak has resulted in more than 5.4 million cases and over 330000 deaths worldwide. Governments responding to a serious disease pandemic might engage in liberty limiting measures including the use of quarantine, sometimes without sufficient legal ${ }^{1}$ or ethical justification. ${ }^{2}$ But quarantine offers an opportunity to develop an understanding of covid-19 that might otherwise not be possible, through the study of disease course and transmission. Research on individuals and groups in quarantine raises distinct ethical issues that require balancing the rights of confined people against the scientific and social value such research could produce.
\end{abstract}

\section{Covid-19 and quarantine}

As cases of covid-19 rapidly increased worldwide, swift action was necessary to mitigate the worst of the outbreak. This included use of quarantine-the separation and confinement of movement of people who, although not yet ill, have been exposed to an infectious agent and might become infectious. Unlike social distancing measures, such as stay at home orders and business closures, quarantine is substantially more restrictive in that individuals or groups are totally confined except in cases of emergency. ${ }^{2}$ The US Centers for Disease Control and Prevention's guidance on quarantine includes measures for providing essential goods and services to obviate the need to access food, water, and medical services, among other things. ${ }^{3}$ Very large geographic restrictions such as the one used to restrict travel to and from Wuhan in China in the early phase of the covid-19 pandemic, sometimes called cordon sanitaire, are closely related to quarantine actions. ${ }^{4}$

Quarantine can control the spread of disease: the quarantine of family members of patients with covid- 19 was modelled to reduce demand for intensive care beds and deaths from the disease, when combined with other interventions. ${ }^{5}$ But quarantine can imperil individual rights through confinement, ${ }^{6}$ especially when governments use community quarantines that confine large numbers of exposed but healthy people alongside those who are ill. On 3 February 2020, for example, the British cruise ship Diamond Princess reported that a previous guest had become ill and was diagnosed with covid-19. The Japanese ministry of health declared a two week quarantine on the ship in the port in Yokohama. Ultimately, 713 passengers and crew members were confirmed as having covid-19, 13 of whom died. ${ }^{7}$ To be ethically justified, quarantine must be at minimum necessary and effective, a proportionate response to the risk of disease, and the least infringing measure available. ${ }^{8}$ Historically, quarantine can exacerbate an outbreak if implemented poorly as people who would not otherwise contract the disease are exposed repeatedly to those carrying a virus or by encouraging recidivism or reluctance to report symptoms to public health authorities. ${ }^{3}$ It might also be replaced or supplemented with less invasive measures, such the Republic of Korea's approach to covid-19 using testing, contact tracing, and case isolation. ${ }^{9}$

Some quarantine actions may be a violation of the International Health Regulations. The World Health Organization's current guidance on covid-19 includes provisions for quarantining individuals who have had close contact with a patient with laboratory confirmed covid-19 either two days before or up to 14 days after the onset of symptoms, for 14 days from their last contact with the patient. ${ }^{10}$ Under the International Health Regulations, states are permitted to take measures beyond WHO's recommendations but must submit evidence to WHO justifying those measures. ${ }^{11}$ States that pursue city-wide or other community quarantines, for example, without submitting evidence to WHO might thus be in violation of the International Health Regulations. Ethically and legally, quarantine measures are rarely justified in the case of covid-19, though arguably this justification may be greater (if non-ideal) in the case of nations that lack capacity or fail through a lack of political will to pursue less invasive strategies-such as mass mobilisation of testing, contact tracing, and isolation-when there was still a chance to do so.

\section{The ethics of research in a quarantine zone}

It is, then, perhaps perverse that quarantine provides a model community in which to study both the social and epidemiological characteristics of a disease outbreak: a closed group of individuals exposed to or thought to have been exposed to disease, with well defined index cases and the capacity to 
closely monitor interpersonal interactions and accurately determine when individuals are infected. These features are ideal to study the relation between viral shedding and the development of symptoms, ${ }^{12}$ which is, among other things, critical to understanding when quarantines are effective and proportionate responses. ${ }^{13}$ One retrospective study currently in preprint, on passengers from the Diamond Princess transferred to the Self-Defense Central Hospital in Japan, mentions the ability to observe the clinical course of asymptomatic and mild cases previously not subject to detailed study as a strength of the research; ${ }^{14}$ another has been conducted on chest computed tomography findings on passengers from the ship. ${ }^{15}$ But perhaps most paradoxical is that the Diamond Princess's poor design as a quarantine setting is what might have made for a useful model system of community transmission of covid- 19 .

The scientific and social value of research is in tension with the coercive nature of quarantine. The ethics of clinical research are well established, ${ }^{16}$ but individuals under quarantine are distinctly vulnerable to researchers. Like prisoners, their confinement could affect their ability to make a truly voluntary and uncoerced decision whether or not to participate in research. ${ }^{17}$ Like research on patients put into isolation by healthcare practitioners, research inside quarantines concerns people under the control of public health authorities; unlike isolation, people under quarantine are not necessarily ill and might not benefit from clinical care or close medical observation. $^{18}$

Research on vulnerable people is hardly new to bioethics. ${ }^{19}$ If governments are already committed to quarantine or require it given their failure to contain the virus, research on quarantined individuals could at least allow for the production of scientifically and socially valuable knowledge, albeit in the context of a serious infringement on human rights. Navigating this tension requires adapting our principles to this new context.

Further concerns for research inside quarantine are fair participant selection, informed consent, and respect for potential and enrolled participants. People in quarantine are a "captive participant pool," and those in poorly designed community settings such as the Diamond Princess are particularly vulnerable in the sense that people who do not participate in the research are not spared its risks - that is, potential exposure to an infectious disease..$^{20} \mathrm{~A}$ well designed quarantine can impose little risk, ${ }^{21}$ but this depends on the size of the quarantine, the resources available to manage it, and the design of the facility - the Diamond Princess being a cautionary tale for governments considering quarantine due to its high population density, lack of preparation and resources for quarantine, and arguably the impossibility of ensuring appropriate infection control on a vessel designed to funnel people into congregate settings (ballrooms, buffets, and so on). Even when people consent or even benefit from quarantine-as they might if they are closely monitored and receive supportive care and medical interventions-researchers might exploit the situation by benefiting from the injustice experienced by participants. ${ }^{22}$

Research inside quarantine must first have major social and scientific value. Quarantine offers the opportunity to record a rigorous account of the infection, its incubation, and the symptomatic presentation of disease from its earliest moments, as well as the relation between this course and the disease's spread in a closed community. Because quarantine in the community might expose people to infection (if they are confined to areas with people who are or will become ill), this research can provide an understanding of the transmission dynamics of a disease in the context of a quarantined population. The scientific benefit of quarantine as a model system from which an inference can be drawn about transmission dynamics in other contexts dovetails into one of the social benefits: clarifying when quarantine is, or is not, effective and proportionate. Producing high quality data on the transmission dynamics of covid-19 would be particularly valuable because we still don't know how often it transmits in the absence of symptoms, ${ }^{23}$ which will determine the degree to which quarantine is justified. ${ }^{3}$

Research of minimal risk must also promote the interests of those in or at risk of quarantine, or at least it must not compromise their interests. Research that constitutes routine medical care, such as through blood draws and case histories, does not compromise the interests of those in quarantine and might benefit individuals in the study and others by giving healthcare workers a chance to isolate a patient before they develop symptoms or transmit the virus. The development of more narrow and targeted quarantine strategies might benefit individuals in quarantine by triggering their release or obviating the need for quarantine in the first place.

For research of greater than minimal risk, promoting the interests of the people who are confined is more contentious. In the context of covid-19, quarantined people might seem to be a useful participant pool for vaccine trials. Although a viable vaccine could benefit people in quarantine, testing vaccines inside quarantine zones should be approached carefully. The promise of being vaccinated might lead to misconceptions that vaccination entails release from quarantine, that enrolment means receiving the vaccine (in placebo controlled studies), or that receiving the vaccine is the safer of the two arms-all of which are false. Vulnerable participants have in the past accepted unfavourable risk-benefit ratios by, for example, taking part in trials that lack adequate safety or efficacy data as a way to secure other benefits, and that concern persists here. ${ }^{24}$

The distinct risks posed by research on people in quarantine provides a reason to modify the procedure under which we approve research, to promote the interests of confined people. In the United States, when conducting research on prison populations, a prisoner must serve as a member on the Institutional Review Board. ${ }^{25}$ This provides a template for quarantined communities to participate in research design and approval: one or more people under quarantine could participate in Institutional Review Board deliberations, to protect the welfare of people in quarantine and allow research to proceed while avoiding marginalisation or harm. Quarantine guidelines require allowing people communication with the outside world, ${ }^{10}$ these services could be leveraged or enhanced to give people the ability to participate in deliberations.

\section{Conclusions}

Quarantine provides an opportunity to gain scientific knowledge of covid-19 that might otherwise be inaccessible. Engaging in research inside quarantine, however, poses serious ethical issues.

People in quarantine can be victims of injustice. They are confined without being convicted of a crime or committing some other wrong, in a way that frequently fails to achieve a substantive public health goal. In the context of covid-19, they might be confined because lack of political will to aggressively and proactively tackle the pandemic has left few other options.

A final consideration is how we recognise the background injustices that might enable this research. Medical ethics is replete with examples of valuable scientific information being gained on the backs and with the bodies of people experiencing injustices and human rights violations. We shouldn't presume that research inside quarantine will be egregious; nonetheless, 
these data are possible because of the violation (or infringement) of civil and human rights. This is particularly true given that quarantine actions in the case of covid-19 are necessary primarily because of governments' failure to respond to the threat of disease in timely and less invasive ways. Explicitly acknowledging these wrongs should be part of ethical research. Data produced from research inside quarantine could be published with a preamble noting the conditions under which the research was conducted and acknowledging the contributions of anonymous, quarantined participants to life saving science. ${ }^{20}$ This does not obviate the harms of quarantine, but rather provides a basis for remembering the dark origins of valuable scientific information. Covid-19 will be remembered as part of the history of global public health. We should recognise the role that confined people play in solving this public health emergency.

\section{Key messages}

- Quarantine is the confinement of people who have been exposed to a disease to prevent them from spreading it further

- It has been used and will likely be used again to respond to covid-19

- As a closed system, quarantine offers the possibility for highly controlled research into the development and transmission of covid-19

- But quarantine is an infringement on individual rights, and thus raises ethical concerns and requires compelling justification to be used

Contributors and sources: This essay was researched, developed, written, and edited by NGE. Thanks to Marc Lipsitch and Theodore Cohen for comments on an earlier draft. All errors or oversights remain that of the author.

Competing interests: I have read and understood BMJ policy on competing interests and have none to declare.

Patient and public involvement: The material described in this Analysis does not directly involve patient care or patient communities.

1 Gostin LO, Hodge JGJr. US emergency legal responses to novel coronavirus: balancing public health and civil liberties. JAMA 2020;323:1131-2. 10.1001/jama.2020.2025 32207808

2 Hills K. Rejecting quarantine: a frozen-in-time reaction to disease. MIT Press, 2016. https: //covid-19.mitpress.mit.edu/pub/m7yo4pdk/release/1

3 US Centers for Disease Control and Prevention. Order for Quarantine Under Section 361 of the Public Health Service Act 42 Code of Federal Regulations Part 70 (Interstate) and Part 71 (Foreign). US Department of Health and Human Services. 2020. https://www.cdc. gov/quarantine/pdf/Public-Health-Order_Generic_FINAL_02-13-2020-p.pdf.

4 Gostin LO. Could-or should-the government impose a mass quarantine on an American city? Health Aff 2020;10. https://www.healthaffairs.org/do/10.1377/hblog20200310.824973/ full/.
5 Ferguson NM, Laydon D, Nedjati-Gilani G, et al. Impact of non-pharmaceutical interventions (NPIs) to reduce covid-19 mortality and healthcare demand. 16 March 2020. https://www. imperial.ac.uk/media/imperial-college/medicine/sph/ide/gida-fellowships/lmperial-CollegeCOVID19-NPI-modelling-16-03-2020.pdf

6 Selgelid MJ. Ethics and infectious disease. Bioethics 2005;19:272-89. 10.1111/j.1467-8519.2005.00441.x 16167406

7 WHO. Coronavirus disease 2019 (covid-19) situation report 120 https://www.who.int/docs/ default-source/coronaviruse/situation-reports/20200519-covid-19-sitrep-120.pdf? sfvrsn $=515 \mathrm{cabfb} \_2$

8 Childress JF, Faden RR, Gaare RD, etal . Public health ethics: mapping the terrain. $J$ Law Med Ethics 2002;30:170-8. 10.1111/j.1748-720X.2002.tb00384.x 12066595

$9 \mathrm{Kim} \mathrm{H}, \mathrm{Kim} \mathrm{S}$, Che $\mathrm{C}$. Virus testing blitz appears to keep Korea death rate low. Bloomberg.Com 2020 Mar 4. https://www.bloomberg.com/news/articles/2020-03-04/southkorea-tests-hundreds-of-thousands-to-fight-virus-outbreak.

10 WHO. Considerations for quarantine of individuals in the context of containment for coronavirus disease (covid-19). https://www.who.int/publications-detail/considerationsfor-quarantine-of-individuals-in-the-context-of-containment-for-coronavirus-disease-(covid19).

11 WHO. International Health Regulations 2005:34. https://www.who.int/ihr/publications/ 9789241580496/en/

12 Lau LL, Cowling BJ, Fang VJ, etal . Viral shedding and clinical illness in naturally acquired influenza virus infections. J Infect Dis 2010;201:1509-16. 10.1086/652241 20377412

13 Peak CM, Childs LM, Grad YH, Buckee CO. Comparing nonpharmaceutical interventions for containing emerging epidemics. Proc Natl Acad Sci U S A 2017;114:4023-8. 10.1073/pnas.1616438114 28351976

14 Tabata S, Imai K, Kawano S, et al. The clinical characteristics of covid-19: a retrospective analysis of 104 patients from the outbreak on board the Diamond Princess cruise ship in Japan. MedRxiv [Preprint] https://www.medrxiv.org/content/10.1101/2020.03.18. 20038125v2

15 Inui S, Fujikawa A, Jitsu M, etal . Chest CT findings in cases from the cruise ship Diamond Princess with coronavirus disease 2019 (covid-19). Radiology: Cardiothoracic Imaging 2020;2:e200110. 10.1148/ryct.2020200110.

16 Emanuel EJ, Wendler D, Grady C. What makes clinical research ethical? JAMA 2000;283:2701-11. 10.1001/jama.283.20.2701 10819955

17 Gostin L, Vanchieri C, Pope A. Ethical considerations for research involving prisoners. National Academies Press, 2007.

18 Fidler DP, Gostin LO, Markel H. Through the quarantine looking glass: drug-resistant tuberculosis and public health governance, law, and ethics. J Law Med Ethics 2007:35:616-28, 512. 10.1111/j.1748-720X.2007.00185. × 18076513

19 Moreno J. Undue risk. Routledge, 201310.4324/9780203388464

20 Centers for Disease Control and Prevention. SARS, CDC guidance supplement D: community containment measures, including non-hospital isolation and quarantine. $8 \mathrm{Feb}$ 2019. https://www.cdc.gov/sars/guidance/d-quarantine/community.html.

21 Diamond B. SARS spreads new outlook on quarantine models. Nat Med 2003;9:1441-1441. 10.1038/nm1203-1441a 14647502

22 Valdman M. Exploitation and injustice. Soc Theory Pract 2008;34:551-7210.5840/soctheorpract200834430.

23 Kupferschmidt K. Study claiming new coronavirus can be transmitted by people without symptoms was flawed. Sciencehttps://www.sciencemag.org/news/2020/02/paper-nonsymptomatic-patient-transmitting-coronavirus-wrong.

24 Alenichev A, Nguyen V-K. Precarity, clinical labour and graduation from Ebola clinical research in West Africa. Glob Bioeth 2019;30:1-18. 10.1080/11287462.2019.1566973 30692879

2545 CFR 46.304. Composition of Institutional Review Boards where prisoners are involved. https://www.law.cornell.edu/cfr/text/45/46.304

This article is made freely available for use in accordance with BMJ's website terms and conditions for the duration of the covid-19 pandemic or until otherwise determined by BMJ. You may use, download and print the article for any lawful, non-commercial purpose (including text and data mining) provided that all copyright notices and trade marks are retained.

https://bmj.com/coronavirus/usage 